\title{
CONTRIBUIÇÕES DA MATEMÁTICA PARA A GESTÃO DOS EMPREENDIMENTOS ECONÔMICOS SOLIDÁRIOS
}

\author{
CONTRIBUTIONS OF MATHEMATICS TO SOLIDARY ECONOMIC \\ ENTERPRISES MANAGEMENT
}

Rafael Pires Pinheiro ${ }^{1}$

ORCID iD: 0000-0002-0061-9159

Andreia Aparecida Guimarães Strohschoen ${ }^{2}$

ORCID iD: 0000-0002-4273-9933

\begin{abstract}
RESUMO
Os Empreendimentos Econômicos Solidários (EES) mostram-se como alternativa para a inclusão da população marginalizada, pois se aproximam das pessoas com experiências práticas e sugerem soluções coletivas através de iniciativas próprias. Esse artigo objetiva refletir sobre ações pedagógicas voltadas ao Ensino de Matemática no contexto dos EES, desenvolvendo, com gestores de EES, conceitos matemáticos buscando contribuir com a efetivação da autogestão dos EES do município de Parauapebas/PA. Trata-se de uma pesquisa qualitativa, cunho exploratório e descritivo, através de grupo focal e oficinas de estudo de conceitos matemáticos. A análise dos dados ocorreu com a Análise de Conteúdos. Identificou-se as categorias de análise: falta de formação básica dos gestores; autogestão dos EES de forma intuitiva. Com a realização das oficinas, pôde-se desenvolver conceitos matemáticos valorizando os conhecimentos culturais dos gestores e inserindo práticas assertivas para a autogestão.
\end{abstract}

Palavras-chave: Matemática Escolar. Empreendimentos. Autogestão.

\section{ABSTRACT/ RESUMEN}

Solidary Economic Enterprises (EES) are shown as an alternative for the inclusion of the marginalized population, as they approach people with practical experiences and suggest collective solutions through their own initiatives. This article aims to reflect on pedagogical actions aimed at Teaching Mathematics in the context of EES, developing, with EES managers, mathematical concepts seeking to contribute to the effectiveness of self-management of EES in the municipality of Parauapebas / PA. It is a qualitative research, exploratory and descriptive, through a focus group and workshops on the study of mathematical concepts. Data analysis occurred with Content Analysis. The analysis categories were identified: lack of basic training for managers; self-management of EES in an intuitive way. With the realization of the workshops, it was possible to develop mathematical concepts valuing the managers' cultural knowledge and inserting assertive practices for self-management.

Keywords/Palabras clave: School Mathematics. Enterprises. Self-management.

\footnotetext{
${ }^{1}$ Doutorando em Ensino de Ciências Exatas (UNIVATES) e Professor EBTT do Instituto Federal de Educação, Ciência e Tecnologia do Pará (IFPA) Campus Parauapebas. Av. Avelino Tallini, 171, Bairro Universitário. Lajeado/RS. CEP: 95900000. E-mail: rafael.pinheiro@ifpa.edu.br.

${ }^{2}$ Doutora em Ecologia (UFRGS) e Professora dos Programas de Pós-Graduação em Ensino e Ensino de Ciências Exatas da Universidade do Vale do Taquari (UNIVATES) Lajeado/RS. Av. Avelino Tallini, 171, Bairro Universitário. Lajeado/RS. CEP: 95900000. E-mail: aaguim@univates.br.
} 


\section{INTRODUÇÃO}

O mundo do trabalho no Brasil perpassa as relações assalariadas de mercado e proporciona uma variedade de outras atividades econômicas de maneira informal. Alguns fatores como o enfraquecimento do peso do emprego formal e a precarização dos postos de trabalho ao longo dos últimos anos confirmam ainda mais essa realidade heterogênea das formas de ocupação laboral.

Segundo Motchane (2007), por volta da década de 1990, muitos grupos populares, tanto urbanos quanto rurais, que se organizavam de maneira cooperativa e associativa passaram a ser notados no cenário político nacional. Para unificarem o discurso em torno dessa temática decidiram utilizar o termo "economia solidária" com o objetivo de definir iniciativas econômicas populares baseadas na autogestão nas regiões urbana e rural.

Dessa forma, Pereira (2014), afirma que a Economia Solidária surge como uma reação da sociedade a esse cenário econômico atual, ou seja, uma estratégia de sobrevivência ao modo de produção excludente. Essa iniciativa é fundamentada nos princípios da solidariedade, do trabalho coletivo, da cooperação, da sustentabilidade, da prática da autogestão e a centralidade no ser humano.

Conforme Meneguetti (2013), a principal base teórico-metodológica das intervenções de Educação Matemática no âmbito da Economia Solidária tem sido a Etnomatemática. O termo é recente e foi proposto por D'Ambrosio em 1975 como parte de um programa de pesquisa mais amplo que posteriormente foi denominado Programa Etnomatemática.

D’Ambrosio (2005), afirma que o programa é amplo e aborda a geração, a organização, a institucionalização e a difusão de conhecimento. Esse programa originou-se a partir do propósito de ter uma melhor compreensão da história do conhecimento científico e do processo de desenvolvimento dos países periféricos, que passaram pela fase de conquista, colonização e depois subordinação neocolonialista. Meneghetti (2013, p. 52), corrobora com o pensamento de D’Ambrosio e destaca outras aproximações possíveis entre a Economia Solidária e a Etnomatemática, sendo a mais evidente é que "a Educação Matemática pode aproximar-se da Educação em Economia Solidária por meio desse Programa, pois ele visa entender a realidade dentro de um contexto cultural próprio".

Baseado nesse pensamento e levando em consideração a situação socioeconômica do Brasil, que passa por um momento de estagnação, a Economia Solidária através dos Empreendimentos de Economia Solidária (EES) favorece uma possibilidade real de geração de renda, superação da pobreza e inclusão social. A importância para tal estudo ocorre de acordo 
com o pensamento de Moreira (2006), que ressalta que a inclusão social não pode ficar restrita aos programas sociais fora da escola, mas que possamos oportunizar o ensino a todos, sem discriminação. Dessa forma, faz-se necessário dar apoio aos empreendimentos, identificando suas necessidades e possibilitando alternativas para alcançarem sua autogestão.

Concebendo a matemática como atividade também intrínseca ao desenvolvimento de nossas tarefas do cotidiano, esse trabalho que é oriundo da dissertação de mestrado em Ensino de Ciências Exatas do primeiro autor, tem por objetivo geral: refletir sobre ações pedagógicas voltadas ao Ensino de Matemática no contexto dos EES, desenvolvendo, com gestores de EES, conceitos matemáticos buscando contribuir com a efetivação da autogestão dos EES do município de Parauapebas/PA.

\section{REFERÊNCIAL TEÓRICO}

Moreira (2006) afirma que no Brasil a inclusão social é considerada um dos desafios a serem enfrentados, pois ela está presente tanto nas questões envolvendo os bens materiais e culturais, quanto a apropriação do conhecimento quando se trata de questões que envolvem assuntos científicos e tecnológicos. Nesse sentido, a inclusão social pode ser entendida

[...] como a ação de proporcionar para populações que são social e economicamente excluídas... oportunidades e condições de serem incorporadas à parcela da sociedade que pode usufruir esses bens... para que todos os habitantes do país possam viver com adequada qualidade de vida e como cidadãos plenos, dotados de conhecimentos, meios e mecanismos de participação política que os capacitem a agir de forma fundamentada e consciente (MOREIRA, 2006, p. 11).

O combate à exclusão social não deve ocorrer somente por auxílio governamental, mas também por meio de oportunidades oferecidas ao sujeito, de maneira que ele seja o agente na busca de sua dignidade e, por consequência, alcance a melhora de suas condições de sobrevivência (ASSEBURG; GAIGER, 2007).

Com base nesse pensamento, a Economia Solidária mostra-se como alternativa para a inclusão da população marginalizada, pois se aproxima das pessoas com experiências e sugere soluções coletivas através de iniciativas próprias. Segundo Pereira (2014, texto digital) observase que os

Empreendimentos de Economia Solidária são as diversas formas concretas de manifestação da Economia Solidária, ou seja, grupos de pessoas que produzem e comercializam seus produtos com base nos princípios da Economia Solidária. O princípio geral da autogestão é que "todos os que trabalham são donos do 
empreendimento e todos os que são donos trabalham no empreendimento." Esses empreendimentos são os principais protagonistas e público-alvo do Fórum Brasileiro de Economia Solidária.

Nesse sentido, compreendemos os EES como aquelas organizações coletivas e suprafamiliares (associações, cooperativas, empresas autogestionárias, grupos de produção, clubes de trocas e outros), cujos participantes são trabalhadores dos meios urbano e rural que exercem a autogestão das atividades e da alocação dos seus resultados.

Com base nessa ideia, a administração de um empreendimento é coletiva e democrática, isto é, todas as decisões mais importantes são tomadas em conjunto. Schneider (1994), afirma que a doutrina dos EES se situa na linha do dever/ser, não na dimensão impositiva, mas participativa. Os fins e os meios no ambiente dos EES referem-se às responsabilidades dos associados quanto à gestão e a execução técnica, respectivamente, o que exige dos associados comprometidos com o empreendimento como opção de escolha para as suas vidas e para o sistema administrativo que deve ser autônomo, democrático e participativo. Assim, os EES se apresentam como alternativa para resolução de problemas decorrentes do desemprego e a exclusão social, podendo atuar desde os processos de produção, industrialização, comercialização, crédito até a prestação de outros serviços.

Para Nakayasu e Sousa (2004), os EES são baseados na gestão participativa que resulta de ações colaborativas, simultaneamente democráticas, descentralizadas e coordenadas, que envolvem a concepção de uma visão clara em toda a organização, desde o mais alto nível da pirâmide organizacional, até o nível operacional de sua missão, objetivos e do desenvolvimento de planos e estratégias que levem à realização dos objetivos pretendidos.

Ter habilidades, competências e atitudes gerenciais e, considerando que este ambiente não é utópico, se faz necessário para que haja a correta evolução dos empreendimentos solidários. Por modelo de gestão entende-se "um conjunto de variáveis como: estrutura, padrão de liderança, padrão de comunicação, padrão de comprometimento, concepções de planejamento e de controle, que definem a forma como uma organização é estruturada e gerida" (VERGARA, 2009, p. 28).

Nesse sentido, o aprendizado proporciona segurança para a tomada de decisões. Segundo Nakayasu e Sousa (2004), o sucesso de um empreendimento depende muito de quão bem seus gestores sejam capazes de criar uma estrutura que possibilite o gerenciamento do negócio. No entanto, esta estratégia inovadora de gestão coletiva ou participativa dos empreendimentos a partir dos princípios da economia solidária necessita periodicamente, de 
avaliação sobre seus avanços, dificuldades e desafios que precisam ser enfrentados para sua consolidação.

Para Barros (2008), a gestão aprimora a tomada de decisão, este motivo faz com que as ações visem à otimização da atividade produtiva, de seus recursos e da aquisição de insumos, como também, a possibilidade de crescimento e permanência no mercado. O modo de gestão deve estar aliado a estratégias de desenvolvimento, que permitam a inclusão da cooperativa de forma mais dinâmica e próxima do meio mercantil em que está inserida.

A educação desempenha influência sobre a sociedade e na contemporaneidade não é diferente, pois acaba atuando como requisito fundamental ao desenvolvimento dos indivíduos e, por conseguinte, corroborando com a formação do ser humano como um todo. Do ponto de vista de Gadotti (2005), a educação se mostra como requisito principal para os indivíduos que compõem a sociedade obterem acesso aos bens e serviços disponíveis, e assim, concluir que a educação se apresenta como direito dos indivíduos que compõem a sociedade e "o direito à educação é, sobretudo, o direito de aprender" (GADOTTI, 2005, p. 1).

Ubiratan D'Ambrosio (1996, p. 120), corrobora com o pensamento de Gadotti (2005) esclarecendo que

[...] aprender não se resume a dominar técnicas e habilidades e nem à memorização de uma série de explicações e teorias; aprender é "a capacidade de explicar, de apreender e compreender, de enfrentar, criticamente, situações novas" e cada indivíduo organiza seu processo intelectual ao longo de sua história de vida.

Este excerto explicita que o aprendizado de maneira mecânica, apenas como exercícios de habilidades de determinados assuntos, não abrange o conceito total de educação, pois D’Ambrosio (1996) compreende o termo educação como

[...] uma estratégia de estímulo ao desenvolvimento individual e coletivo gerada por esses mesmos grupos culturais, com a finalidade de se manterem como tal e de avançarem na satisfação de necessidades de sobrevivência e de transcendência (D’AMBROSIO, 1996, p. 8).

Baseando-se no pensamento do autor, para fazer sentido deve-se pensar em educação como finalidade de desenvolvimento pleno dos cidadãos. Contudo, não devemos entender o termo 'desenvolvimento pleno' de maneira cingida, ou seja, 'desenvolvimento pleno' não nos remete a índices mais elevados de alfabetização, índices econômicos melhores e controle da inflação, ou ainda a elevação de qualquer um dos índices propostos por estudiosos, como economistas, governantes, filósofos e outros. Para D’Ambrosio (1996), ‘desenvolvimento 
pleno' significa alcançar uma melhor qualidade de vida e uma maior dignidade como um todo, condições que acontecem no momento em que há um encontro entre os indivíduos.

Ubiratan D'Ambrosio (2008) faz uma reflexão sobre a relação entre Educação Matemática e Etnomatemática e conclui que ela ocorre de maneira natural, pois a mesma se mostra como uma maneira de preparar jovens e adultos para o exercício de uma cidadania crítica, para a vida em sociedade e para o desenvolvimento de sua criatividade.

Segundo Meneguetti (2013), a principal base teórico-metodológica das intervenções de Educação Matemática no âmbito da Economia Solidária tem sido a Etnomatemática. Este programa originou-se a partir do propósito de ter uma melhor compreensão da história do conhecimento científico e do processo de desenvolvimento dos países periféricos, que passaram pela fase de conquista, colonização e depois subordinação neocolonialista.

D’Ambrosio (2008) salienta que este é um momento de contestação e de renovação do conhecimento, buscando obter relações éticas entre grupos, comunidades, nações e os próprios indivíduos. Além disso, vale ressaltar que ciência é um processo dinâmico e contínuo e deve passar por constantes autoanálises e atualizações. Assim, o diálogo intercultural e interdisciplinar é o primeiro passo para o pensamento transcultural e o conhecimento transdisciplinar, o que possibilita a sobrevivência com dignidade da espécie humana. Para ele o Programa Etnomatemática representa esse novo pensar (D’AMBROSIO, 2005).

A Etnomatemática é compreendida como a arte ou técnica de entender a realidade, dentro de um contexto cultural próprio. A cultura diz respeito a um conjunto de conhecimentos compartilhados e comportamentos compatibilizados sobre a realidade que se manifesta nas maneiras próprias ao grupo, à comunidade, isto é, na sua Etnomatemática (D’AMBROSIO, 2005). Para o autor supracitado, a etnomatemática ajuda na compreensão do processo cognitivo em uma relação dialética. Assim, todo conhecimento é resultado de um processo cumulativo de geração, de organização intelectual e social, e de difusão. Este processo é dinâmico e nunca está finalizado, pois se trata do "ciclo de aquisição individual e social de conhecimento" que busca no reconhecimento da dinâmica inter e intracultural da sociedade, encontrar ferramentas que deem sentido às ações humanas no cotidiano.

\section{METODOLOGIA}

Trata-se de uma pesquisa qualitativa, cunho exploratório e descritivo, através de grupo focal e oficinas de estudo de conceitos matemáticos, com gestores de EES. Optou-se pela realização de dois grupos focais e o desenvolvimento de oficina com gestores de EES 
participantes do estudo. O grupo focal, segundo Morgan (1996), é uma técnica de pesquisa qualitativa, derivada das entrevistas grupais, que coleta informações das interações grupais. Esses instrumentos serviram para identificar as necessidades dos EES, aperfeiçoar tópicos matemáticos necessários para a gestão, e perceber as contribuições na rotina dos EES. Após a coleta dos dados, esses foram analisados pela Análise de Conteúdo proposta por Bardin (2016).

Inicialmente, os gestores dos EES do município de Parauapebas/BA foram contatados, instruídos quanto aos objetivos desta pesquisa e aqueles que aceitaram participar, assinaram o Termo de Consentimento Livre Esclarecido, que autoriza a participação e divulgação dos resultados da pesquisa. O primeiro grupo focal, aconteceu no dia 10 de julho de 2018 nas dependências do IFPA Campus Parauapebas/PA, com horário pré-agendado para às $18 \mathrm{~h}$, tendo como convidados dois gestores de cada um dos cinco EES participantes desta pesquisa. $\mathrm{O}$ recurso utilizado foi gravação em vídeo, com objetivo de facilitar a análise dos dados.

As questões norteadoras do primeiro grupo focal versavam sobre: a história de criação dos EES no município; principais atividades ou serviços que o EES; quantidade de pessoas envolvidas no EES; como ocorre a gestão (como as decisões são tomadas) dos EES; como funciona a compra de matéria prima para a produção dos produtos ou serviços; como é realizado o controle financeiro em relação as entradas e saídas, custo de produção, cotação de preços etc.; qual a percepção da utilização da matemática escolar no processo de produção e comercialização dos produtos ou serviços prestados pelo EES; dificuldades em relação aos conhecimentos matemáticos na gestão dos EES; principais problemas identificados na gestão dos EES; quais recursos são utilizados na para facilitar a gestão do dos EES.

O segundo grupo focal, aconteceu no dia 29 de outubro de 2018 nas dependências do IFPA Campus Parauapebas/PA, com horário pré-agendado para às 19h, também com dois gestores de cada um dos cinco EES participante da pesquisa, seguindo os mesmos procedimentos que a primeira etapa. As questões desta etapa versavam sobre: a percepção dos participantes em relação à experiência de participar da oficina voltada para a Matemática dentro dos EES; quais os aprendizados na oficina foram levados para o dia a dia dos EES; aplicação dos conhecimentos adquiridos na oficina na gestão dos EES; mudanças na atuação na gestão dos EES após as oficinas; avaliação geral da oficina e pertinência desta.

Para desenvolver conceitos matemáticos necessários à gestão dos EES, com os gestores dos empreendimentos pesquisados, utilizou-se do recurso metodológico Oficina como facilitador no processo de ensino e de aprendizagem, pois os gestores envolvidos, faziam parte do público de jovens e adultos, que participaram de momentos de aprendizagem após uma jornada diária de trabalho. 
A oficina foi dividida em quatro encontros, com periodicidade semanal, e realizada em uma sala de aula do Instituto Federal de Educação, Ciência e Tecnologia do Pará (IFPA) no campus Parauapebas, no período noturno, com duração de duas horas por encontro. A oficina foi direcionada aos gestores dos EES e foi realizada no período noturno em função do público pesquisado, que possuíam ocupações durante o período diurno. As oficinas baseavam-se em conteúdos matemáticos necessários para a gestão de empreendimentos como os em análise.

Nesse estudo utilizou-se as denominações EES-1, EES-2, para designar os empreendimentos. Quanto aos gestores dos empreendimentos por cooperado ou sócio A, B, C e assim por diante. A decisão do substantivo se dá pela caracterização do empreendimento, que nessa pesquisa tem-se por opção cooperativa (utilizaremos a denominação cooperado) ou empreendimento autointitulado econômico solidário (utilizaremos a denominação sócio).

\section{ANÁLISES E RESULTADOS}

Apresenta-se a seguir a análise dos dois grupos focais e a descrição das oficinas desenvolvidos com os gestores dos EES. Após a realização da Análise de Conteúdo, foram obtidas duas categorias de análise, as quais serão apresentadas a seguir: falta de formação básica dos gestores; autogestão dos EES de forma intuitiva. Inicialmente apresenta-se a descrição das oficinas e depois as categorias obtidas após a análise dos dados da pesquisa.

\subsection{Descrição das oficinas}

O primeiro encontro teve início às $18 \mathrm{~h} 00 \mathrm{~min}$ no dia 17 de setembro de 2018 , na sala 07 do IFPA - Campus Parauapebas. Ao iniciar a oficina, com a participação de 11 gestores dos EES, o pesquisador deu boas-vindas aos presentes, expôs o cronograma e objetivos a serem alcançados no encontro.

Prosseguindo, desenvolveu uma técnica de dinâmica com objetivo de que os gestores percebessem a importância da continuidade na gestão dos EES e do comprometimento de cada sócio com as metas coletivas. Nessa dinâmica, o pesquisador solicitou aos participantes que relatassem, em forma de desenho, em uma construção coletiva, seus anseios e objetivos pessoais e/ou profissionais. Porém, nem todos conseguiram contribuir na produção dos desenhos, contudo no memento de partilhar as intenções iniciais e o resultado obtido, eles puderam expor suas expectativas para o futuro dos EES. O Cooperado A verbalizou que gostaria que todos fossem unidos, explicando seu desenho, que se aproximava das características de uma igreja. Já o Cooperado B iniciou a construção do desenho com uma mesa de discussão, ressaltando a 
importância em debater as decisões a serem tomadas. O Cooperado $\mathrm{C}$ explicou que seu desenho não estava bem claro, mas soube expressar seu sonho em ver seus medicamentos caseiros em postos de saúde da região.

Destarte, o pesquisador fez a leitura de um texto motivador, abordando a prática do escambo, e em seguida, propôs uma questão desafio para os grupos de trabalho, que foram organizados em três grupos, sendo dois com quatro e um com três participantes, com duração de $15 \mathrm{~min}$. A questão desafio foi elaborada dentro do contexto cultural dos participantes, com objetivo de oportunizar a utilização dos conhecimentos adquiridos ao longo de sua experiência de vida.

"Questão desafio: O escambo é a mais antiga prática comercial do mundo. Nela, as pessoas trocavam uma mercadoria por outra sem equivalência de valor, pois a moeda (dinheiro), como hoje conhecemos não existia. Assim, por exemplo quando uma criança troca com um colega um brinquedo caro por outro de menor valor, apenas por deseja-lo muito, está praticando uma forma de escambo. Algumas palavras que hoje são familiares provem dessa prática. Apenas para registrar, podemos citar a palavra capital (patrimônio), deriva do latim, capita, que significa cabeça, e a palavra salário, que provém da utilização do sal, em Roma, como pagamento de serviços prestados. Imagine que numa forma particular de escambo realizada por dois EES do município de Parauapebas/PA, uma vassoura feita de garrafa pet correspondesse a 12 maços de cheiro-verde. Quantas vassouras corresponderiam a 60 maços de cheiro-verde?"

Foi solicitado aos gestores que, em seus grupos de trabalho, escrevessem o processo de resolução do desafio. Todos os participantes conseguiram chegar a um resultado satisfatório, chamando a atenção para as formas que conduziram o processo as resoluções. Na resolução do primeiro grupo de trabalho, conforme a Figura 1, percebe-se a falta da linguagem algébrica, porém há uma organização das ideias, mesmo prevalecendo o método por tentativas para alcançar um resultado. 
12 vassouras vall

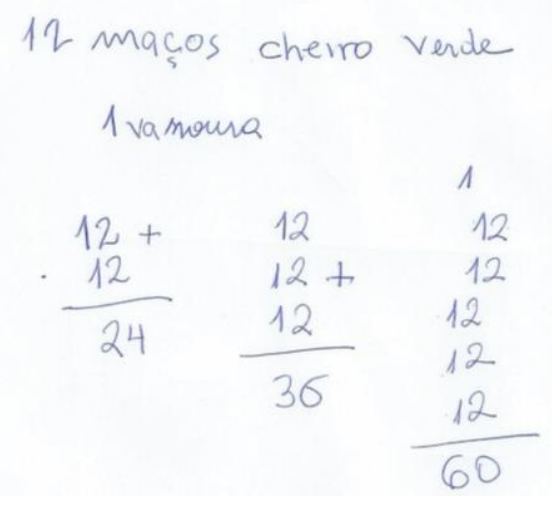

Figura 1 - Resolução da questão desafio do $1^{\circ}$ grupo de trabalho Fonte: Gestores dos EES de Parauapebas/PA, 2018.

O segundo grupo de trabalho conseguiu apresentar uma resposta com maior rigor matemático, tendo o cuidado em especificar o resultado pedido e utilizando dos conceitos de divisão. A Figura 2 deixa evidente que o grupo compreendeu o que foi pedido, porém não conseguiram relacionar a questão desafio com a linguagem algébrica das proporções.

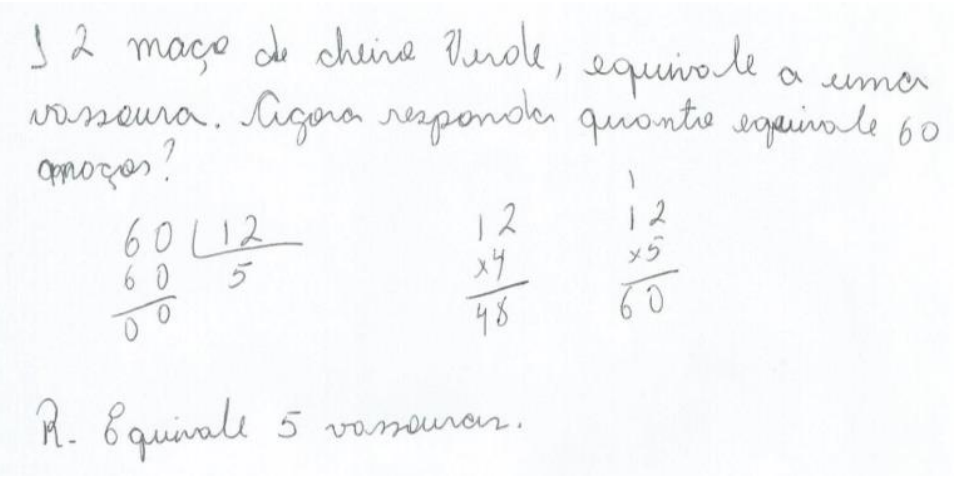

Figura 2 - Resolução da questão desafio do $2^{\circ}$ grupo de trabalho Fonte: Gestores dos EES de Parauapebas/PA, 2018.

Já o terceiro grupo, conforma mostra a figura 3, também chegaram ao resultado esperado, contudo, o grupo conseguiu aplicar a técnica da regra de três simples, o que evidencia o domínio de uma linguagem algébrica que pode facilitar na gestão dos EES. 


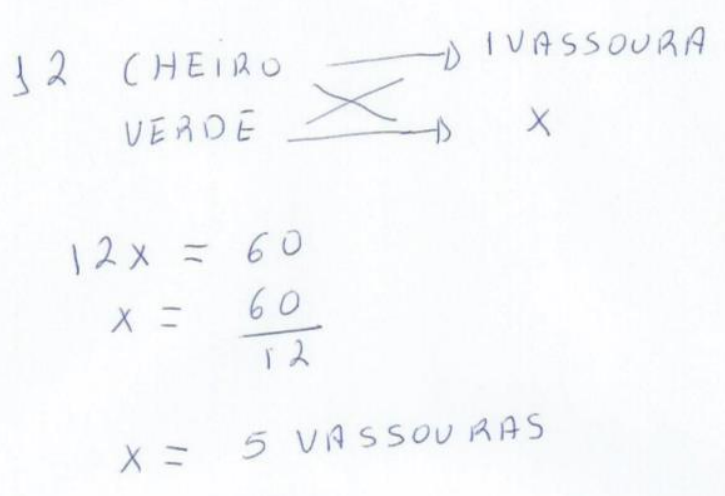

Figura 3 - Resolução da questão desafio do $3^{\circ}$ grupo de trabalho Fonte: Gestores dos EES de Parauapebas/PA, 2018.

Vale ressaltar o empenho dos gestores dos EES ao participar do desafio, o que no início da pesquisa era uma preocupação, pois não acreditavam que seria possível relacionar temas estudados na escola com o seu cotidiano.

Prosseguindo com a oficina, o pesquisador realizou um apanhado geral do tópico abordado na questão desafio, conceituando algumas práticas abordadas e generalizando para situações futuras. Em seguida, os gestores foram motivados a treinarem a técnica estudada com objetivo de oportunizar a todos a resolução de alguma questão.

O segundo encontro teve início às $18 \mathrm{~h} 15 \mathrm{~min}$ no dia 19 de setembro de 2018 , na sala 07 do IFPA - Campus Parauapebas. Ao iniciar, recordou-se os tópicos estudados anteriormente, e em seguida foi dado continuidade ao estudo conceitual do tópico razão e proporção. Para dar início as atividades do dia, o pesquisador trouxe uma questão motivadora, envolvendo a técnica regra de três composta. A saber: "Para asfaltar $1 \mathrm{~km}$ de estrada, 15 homens gastam 12 dias trabalhando 8 horas por dia. Vinte homens, com a mesma capacidade de trabalho, para asfaltar $2 \mathrm{~km}$ da mesma estrada, trabalhando 12 horas por dia, nas mesmas condições, gastarão quantos dias?"

Essa abordagem consistiu em identificar as estratégias de resolução de exercícios e os conhecimentos adquiridos com a sua experiência. Os gestores dos EES continuaram com a mesma formatação dos grupos de trabalho e foi destinado 20 minutos para a resolução e justificativa da questão motivadora.

O primeiro grupo de trabalho foi o único que conseguiu chegar ao resultado esperado, o que ressalta a importância do ensino de matemática fora da escola formal, e a dificuldade enfrentada pelos gestores dos EES do município de Parauapebas/PA. Os membros desse grupo conseguiram de maneira sistemática obter o resultado esperado para a questão motivadora, deixando a interpretação que dominam a técnica da regra de três composta. Porém, foi 
percebido que nem todos os membros do grupo faz jus dessa interpretação, e ressalta a importância de trabalhar o tópico com todos os gestores, pois os EES necessitam que todos os envolvidos possam agregar conhecimentos em sua prática em busca da autogestão.

No segundo grupo de trabalho, utilizaram-se dos conhecimentos da técnica regra de três composta, porém se perderam no momento de identificar as grandezas diretamente e inversamente proporcionais, sugerindo assim, o reforço dos conceitos estudados e a abordagem de novos tópicos. Outro fator relevante do segundo grupo de trabalho é a apresentação da resposta, que foi pedida em dias e apresentada como resultado três virgula seis $(3,6)$ e não em dias e horas (ou submúltiplos: minutos e segundos), o que se leva a entender uma preocupação em aplicar a técnica em não em interpretar o resultado obtido.

Já no terceiro grupo, encontramos uma aplicação da técnica regra de três não finalizada, pois o grupo de trabalho não fez análise das grandezas dadas em relação a grandeza pedida, no sentido de identificar que são diretas ou inversamente proporcionais. Em seguida, os participantes puderam compartilhar o resultado encontrado por seu grupo com os demais, com objetivo de perceber as diferentes formas de pensar matematicamente. Logo após a troca de informações dos resultados o pesquisador trouxe uma abordagem histórica da técnica regra de três para a resolução de questões envolvendo grandezas proporcionais. Dando continuidade, o pesquisador trouxe uma situação fictícia, para que os gestores analisassem uma cooperativa de colheita, baseando-se nos conhecimentos de grandezas proporcionais, e os ajudassem a tomar uma decisão assertiva do ponto de vista da gestão dos EES. Esta questão se tornou um divisor de águas durante a oficina, pois a partir daquele momento, muitos gestores puderam perceber a importância do tópico de grandezas proporcionais para a tomada de decisões no seu EES, pois até então pensavam em situações genéricas que pouco seriam aplicadas em seu cotidiano.

No terceiro encontro, foi relembrado os conceitos estudados na atividade anterior e apresentados os objetivos atuais. Suas atividades iniciaram às $18 \mathrm{~h} 00 \mathrm{~min}$ no dia 24 de setembro de 2018, na sala 07 do IFPA - Campus Parauapebas. Os participantes foram organizados em círculo, para facilitar a exposição de alguns conceitos, e dessa forma, apresentou-se tópicos de gestão e gestão financeira de maneira dialógica. Nesse momento, o pesquisador trouxe algumas perguntas norteadoras da discussão, como: o que é gestão? O que é financeiro? Como saberemos o que entra e o que sai do nosso empreendimento? O que mais traz entrada e saída de dinheiro de nosso empreendimento? O objetivo para tais perguntas era oportunizar a troca de experiências entre os EES, e sugerir algumas práticas que poderia facilitar o trabalho dos gestores e auxiliar na tomada de decisões.

Esse pensamento surgiu devido à grande expectava dos gestores do EES, que durante 
toda a pesquisa, sinalizavam a necessidade de organização financeira e buscavam do pesquisador uma receita para alavancar seu EES. Como essa pesquisa não objetivava fazer trabalho de consultoria, mas sim desenvolver conceitos matemáticos para auxiliar na gestão, pensou-se em dedicar um momento para essa reflexão. Os questionamentos supracitados foram discutidos coletivamente.

O quarto encontro teve início às 18 h00min no dia 26 de setembro de 2018 , na sala 07 do IFPA - Campus Parauapebas e contou com a participação de 11 gestores dos EES. Ao iniciar, o pesquisador relembrou os tópicos estudados anteriormente, e em seguida trouxe a questão norteadora do dia: por quanto devo vender o produto do meu EES? O objetivo para tal questionamento é que os EES possam utilizar os conhecimentos matemáticos para a tomada de decisões. Cada EES teve oportunidade de mapear os custos de um de seus produtos e algumas das respostas será apresentada a seguir. O Cooperado A, do EES-4, trouxe a tabela de gastos referente a um de seus medicamentos caseiros, conforme mostra a Figura 4.

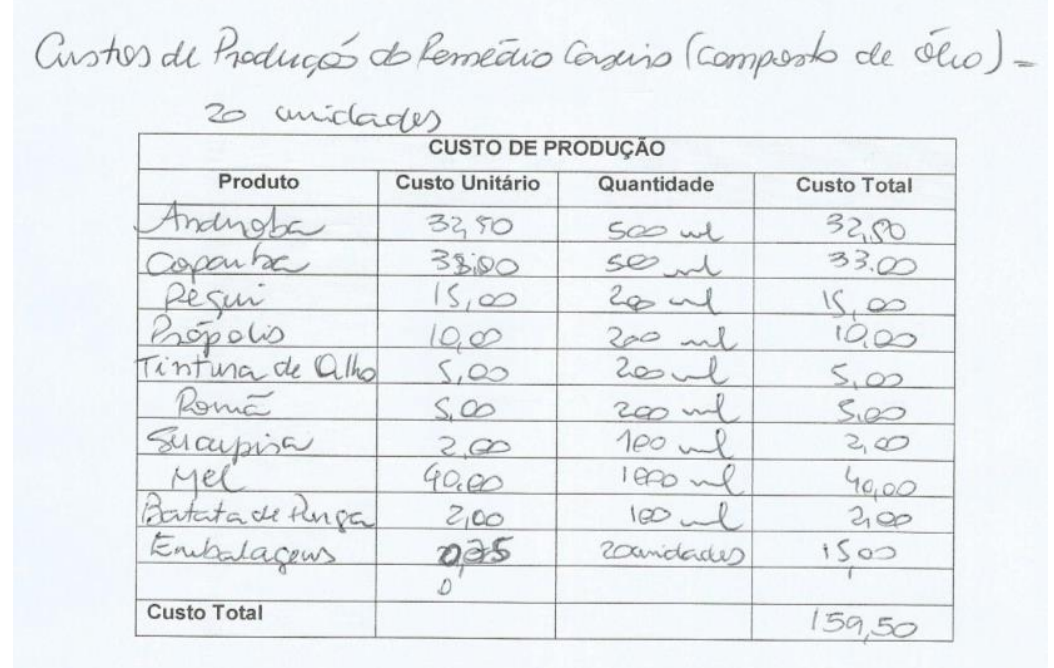

Figura 4 - Resultado do compromisso proposto aos gestores do EES-4 sobre o custo de um de seus produtos Fonte: Gestores dos EES de Parauapebas/PA, 2018.

Nessa figura podemos perceber que o empreendimento citado fez uma estimativa para vinte (20) unidades do produto, tendo como resultado R\$159,50 para o custo de produção. Assim, destaca-se o custo unitário de $\mathrm{R} \$$ 7,975. Outro fator relevante é que o EES-4 não contabilizou um valor para o serviço de produção, para as ferramentas utilizadas, despesas administrativas, segue. Isso nos leva a entender que ainda falta uma compreensão maior, por parte dos gestores, em relação aos custos de produção, pois sem definir o quanto se gasta, dificilmente a escolha do preço de venda será ideal.

O Cooperado B do EES-3, apresentou a tabela de custo de produção de vassouras feitas 
de garrafa pet e percebeu-se que os gestores do EES-3 estimaram um valor unitário para o custo de produção de uma vassoura feita de garrafa pet, sendo de $\mathrm{R} \$ 6,60$. Nesse empreendimento já houve uma preocupação com o pagamento pelo serviço, porém não sabiam ao certo como cobrar pela lâmina, que cortam as garrafas pet para a produção das vassouras. Contudo, após discussões, estimaram de maneira intuitiva, baseado na quantidade de garrafas que uma lâmina pode cortar, o preço da lâmina por vassoura.

A Sócia A do EES-2, mostrou a tabela de custo de produção de um canteiro de cheiroverde, que atinge duzentos (200) maços em média e, nesse empreendimento, destaca-se a falta de estimar um valor para o serviço, pois os gestores não souberam definir, acreditando que deveria apenas tirar as despesas e o restante ser considerado o preço pelo serviço. Esse grupo também se baseou na intuição para definir os gastos de água, ferramentas e madeira, o que resultou em um custo de $\mathrm{R} \$ 297,80$ para a produção de duzentos (200) maços de cheiro-verde, sendo o custo unitário de $\mathrm{R} \$ 1,489$.

Ao final das apresentações, os EES do município de Parauapebas/PA puderam perceber a importância de exercitar as anotações sobre o custo de produção dos seus produtos, pois quando a análise é feita com uma grande margem de erro, não é possível ter precisão no preço de venda e nem na identificação da viabilidade do negócio. Vale ressaltar que muitos gestores perceberam que não precisam de uma pessoa externa para dizer se o negócio é viável, onde precisa diminuir os gastos ou quanto poderá ser cobrado por um produto, pois a experiência dos gestores, a busca por novos conhecimentos e a prática deles, são necessários para uma decisão assertiva.

Após o desenvolvimento da oficina, a maioria relatou que não se animaram a princípio, pois estavam receosos em estudar matemática, associando a forma e métodos em que aprenderam. Esse relato vem ao encontro do pensamento de Brandão (1986) que afirma "[...] muitos educadores pensam a Educação em domínios restritos: a universidade, o Ensino Médio, o Ensino Fundamental, a Alfabetização, a Educação de Jovens e Adultos”. Dessa forma, para este autor, muitas vezes a Educação direciona-se por esses domínios restritos, determinados socialmente, quando deveria atender às necessidades do contexto, do cotidiano do aluno, enfim, da cultura do educando. Neste sentido, a Cooperada C do EES-2 relata que:

Eu particularmente gostei muito das oficinas, pois quando você [pesquisador] foi nos procurar para participar e falou em aprender matemática eu já fiquei preocupada, porque não sei muita coisa, e quando a gente estudava [na escola formal] sempre caia umas coisas que nunca usei. Na verdade, nós perdemos muita coisa por falta do conhecimento (COOPERADA C). 
O comentário da Cooperada C, nos mostra uma situação bastante comum no ensino de matemática, que é a imagem negativa desta área do conhecimento, baseada na experiência vivida na escola formal. Também vale ressaltar, a percepção da Cooperada $\mathrm{C}$ em relação a importância da educação para a mudança social, o que corrobora com a fala de Meneghetti e Daltoso Jr. (2013) que aborda a Educação como uma forma de estímulo ao desenvolvimento individual e coletivo, gerada por grupos culturais, com a finalidade de se manter como tal e de avançar na satisfação dessas necessidades de sobrevivência e de transcendência.

Assim, o Cooperado D do EES-4, relata o processo de desconstrução das escolhas somente pela intuição, pois perceberam durante a pesquisa que é necessário calcular os passos que serão dados, para que se tenha o menor erro possível.

\begin{abstract}
Nós temos um costume de decidir as coisas pelo impulso, nem sempre calculamos os passos que vamos dar. Eu penso que devemos refletir mais sobre as decisões pois é a vida do empreendimento que está em jogo. Na oficina consegui lembrar de algumas coisas que estudei no colégio, mais poucas vezes utilizei para me ajudar na gestão (COOPERADO D).
\end{abstract}

Garcia (1981) reforça a argúcia do Cooperado D, afirmando que ao planejar, o cooperado preserva a ideia de que a cooperativa não deve trabalhar de maneira improvisada, pois quando se opta pelo planejamento antecipadamente, os objetivos que devem ser atingidos se tornam claros e possíveis de alcançá-los. A Cooperada E, do EES-3 contribuiu com o momento de reflexão contando as suas expectativas quando foi convidada a participar dessa pesquisa.

\footnotetext{
Eu vim com a expectativa de que o professor fosse resolver nossos problemas, pois ele chegou falando de matemática, que ia nos ajudar, eu fiquei empolgada logo, mais quando participei da oficina, percebi que nós da gestão, que acordamos cedo todos os dias, e dependemos dessa renda que temos que buscar oportunidades de conhecer mais e aplicar o que aprendemos, porque matemática é importante e está presente em todo momento, então porque não utilizar em nosso favor? (COOPERADA E).
}

Percebe-se nesse comentário, que a Cooperada E ainda não se identificava como sujeito de sua própria transformação no início da pesquisa, pois buscava em alguém a oportunidade de ascensão do seu negócio, o que muitas vezes leva, mesmo com conhecimentos disponíveis, a morosidade das ações, deixando assim, de empreender e praticar novos métodos de gestão. Durante a entrevista, percebeu-se a mudança de algumas práticas dos gestores dos EES do município de Parauapebas/PA, e dessa forma, optou-se em apresentar as mudanças. Nesse contexto, a Cooperada F relata a importância de um diário de produção, ou diário de trabalho, abordados durante o terceiro encontro, e afirma: 
O que mais mudou no nosso dia a dia foram as anotações. Antes pensávamos que era preciso treinamento, um material especifico, mais com as dinâmicas percebemos que em uma simples folha de papel podemos registrar o que acontece no empreendimento. Às vezes não dá tempo para anotar. Mas ajuda bastante ter esse controle, porque lá na frente podemos ver o que fizemos de errado e mudar (COOPERADA F).

Com base no excerto, ficou claro os resultados alcançados durante a oficina, que objetivava de sobremaneira dar apoio aos empreendimentos econômicos solidários, em relação aos conhecimentos matemáticos necessários em busca da autogestão. É importante ressaltar que essa pesquisa não esgota as possibilidades de busca de conhecimentos matemáticos para a gestão, pois há muitos tópicos que não foram abordados, pelo tempo disponível, e poderiam auxiliar ainda mais o cotidiano dos EES de Parauapebas/PA. Seguindo esse pensamento, fica evidente o posicionamento de Duarte (2004), que mostra a aprendizagem não mais como uma simples aquisição de técnicas e habilidades ou como memorização de determinadas explicações ou teorias, mas como a capacidade de explicar, apreender, compreender e enfrentar criticamente situações novas, de modo que cada indivíduo organiza seu processo intelectual ao longo de sua história de vida.

Assim, toda ação, mesmo que singela, realizada pelos gestores participantes da pesquisa, em seu EES, foi considerada como um bom resultado para o pesquisador, pois na região de Carajás, a qual estamos inseridos, falta políticas públicas para o incentivo da economia solidária, falta oportunidades de formação para grupos marginalizados e consequentemente oportunidades para que pessoas em situação de vulnerabilidade social possam ter opção de sobrevivência. O Cooperado G do EES-4 relata a aplicação de conceitos matemáticos necessários para a gestão, e reforça a ampliação de seu pensamento matemático, que antes limitava-se a compra e venda de produtos e agora na tomada de decisões.

\footnotetext{
Nós sempre usávamos a matemática para passar um troco, somar as despesas, o dinheiro que entrou. Mais não tínhamos percebido a importância para tomar decisões. Agora quando um produto básico para a produção está mais caro pensamos duas vezes antes de comprar, pois vai ter um impacto na venda e no lucro (COOPERADO G).
}

Outro ganho para os EES é a percepção da matemática como ferramenta para auxiliar nas decisões, pois muitos tiveram contato com a matemática somente na escola formal, sem fazer aplicações, e outros conhecem uma matemática dentro do seu contexto cultural, porém não a reconhece como a disciplina apresentada nos componentes curriculares.

Fica evidente a escolha assertiva de uma abordagem etnomatemática para o ensino nos EES, pois o grupo de gestores são adultos com uma grande carga cultural, que possivelmente 
não seriam alcançados pelo ensino clássico. É importante que o professor, não só ao coordenar oficinas, seja sensível e perceba que vale a pena buscar práticas que valorize os conhecimentos adquiridos pelos alunos, para que dessa forma sejam mais motivados e sujeitos do processo de aprendizagem (PINHEIRO; STROHSCHOEN, 2019).

\section{2 Categorias de análise}

\subsubsection{Formação básica para a gestão}

Durante a realização do primeiro grupo focal percebeu-se que a maioria dos EES pesquisados ainda não possuíam um mecanismo que os satisfizessem para a gestão, o que acabava desmotivando alguns sócios, levando-os até a abandonarem suas atividades. Assim, é esclarecedor o comentário do Cooperado B, do EEE-5 que afirma: “[...] Já fui secretário, tesoureiro e já fui presidente... a grande dificuldade das cooperativas daqui é ter as pessoas certas no lugar certo. O que falta, que eu gostaria de reforçar, é formação".

Com base nesse comentário, identificamos o rodízio das funções de gestão com as mesmas pessoas e a falta de conhecimentos para exercer determinada tarefa, pois muitas vezes os EES sofrem com a carência de pessoas que aceitem o cargo, o que acaba comprometendo o andamento das atividades e mantendo as mesmas pessoas à frente do negócio sem compreensão das funções exercidas.

O pensamento de Machado (2006), vem ao encontro da fala do Cooperado B, do EES5, e afirma que em tempos de competitividade e concorrência é preciso buscar novos conhecimentos e aprender cada vez mais a gerir os empreendimentos com mais eficiência e transparência, assim como ter uma ampla visão de mercado, pois a gestão é um conjunto de ações que poderão garantir um alcance nos objetivos determinados pelas entidades, tais como: planejamento, controle e principalmente tomada de decisão.

\subsubsection{Autogestão dos EES de forma intuitiva}

Notou-se que a realidade da maioria dos EES pesquisados demonstra, ainda, que o desenvolvimento das práticas de gestão se dá de forma intuitiva, pois nem sempre há clareza no planejamento das ações e as decisões são tomadas de maneira aleatória. A Sócia A do EES2 esclarece os procedimentos realizados na gestão: 
canteiros de coentro e não tínhamos a cebolinha para montar o cheiro verde e aí tivemos que comprar cebolinha de outros canteiros (SÓCIA A).

Nesse comentário, fica evidente a necessidade de ir em busca de conhecimentos, principalmente em relação a matemática, que possam agregar informações na tomada de decisão, pois para Nakayasu e Sousa (2004), o aprendizado proporciona segurança para a tomada de decisões e o sucesso de um empreendimento depende muito de quão bem seus gestores sejam capazes de criar uma estrutura que possibilite o gerenciamento do negócio.

O Cooperado D do EES-4, relata o processo de desconstrução das escolhas somente pela intuição, pois perceberam durante a pesquisa que é necessário calcular os passos que serão dados, para que se tenha o menor erro possível.

Nós temos um costume de decidir as coisas pelo impulso, nem sempre calculamos os passos que vamos dar. Eu penso que devemos refletir mais sobre as decisões pois é a vida do empreendimento que está em jogo. Na oficina consegui lembrar de algumas coisas que estudei no colégio, mais poucas vezes utilizei para me ajudar na gestão (COOPERADO D).

Garcia (1981) reforça a argúcia do Cooperado D, afirmando que ao planejar, o cooperado preserva a ideia de que a cooperativa não deve trabalhar de maneira improvisada, pois quando se opta pelo planejamento antecipadamente, os objetivos que devem ser atingidos se tornam claros e possíveis de alcançá-los.

A Cooperada E, do EES-3 contribuiu com o momento de reflexão contando as suas expectativas quando foi convidada a participar dessa pesquisa.

\footnotetext{
Eu vim com a expectativa de que o professor fosse resolver nossos problemas, pois ele chegou falando de matemática, que ia nos ajudar, eu fiquei empolgada logo, mais quando participei da oficina, percebi que nós da gestão, que acordamos cedo todos os dias, e dependemos dessa renda que temos que buscar oportunidades de conhecer mais e aplicar o que aprendemos, porque matemática é importante e está presente em todo momento, então porque não utilizar em nosso favor? (COOPERADA E).
}

Percebe-se nesse comentário, que a Cooperada E ainda não se identificava como sujeito de sua própria transformação no início da pesquisa, pois buscava em alguém a oportunidade de ascensão do seu negócio, o que muitas vezes leva, mesmo com conhecimentos disponíveis, a morosidade das ações, deixando assim, de empreender e praticar novos métodos de gestão. Durante a entrevista, percebeu-se a mudança de algumas práticas dos gestores dos EES do município de Parauapebas/PA. Nesse contexto, a Cooperada F relatou a importância de um diário de produção, ou diário de trabalho, abordados durante o terceiro encontro, e afirma: 
O que mais mudou no nosso dia a dia foram as anotações. Antes pensávamos que era preciso treinamento, um material especifico, mais com as dinâmicas percebemos que em uma simples folh a de papel podemos registrar o que acontece no empreendimento. Às vezes não dá tempo para anotar. Mas ajuda bastante ter esse controle, porque lá na frente podemos ver o que fizemos de errado e mudar (COOPERADA F).

Com base no excerto, ficou claro os resultados alcançados durante a oficina, que objetivava de sobremaneira dar apoio aos empreendimentos econômicos solidários, em relação aos conhecimentos matemáticos necessários em busca da autogestão. É importante ressaltar que essa pesquisa não esgota as possibilidades de busca de conhecimentos matemáticos para a gestão, pois há muitos tópicos que não foram abordados, pelo tempo disponível, e poderiam auxiliar ainda mais o cotidiano dos EES de Parauapebas/PA.

Seguindo esse pensamento, fica evidente o posicionamento de Duarte (2004), que mostra a aprendizagem não mais como uma simples aquisição de técnicas e habilidades ou como memorização de determinadas explicações ou teorias, mas como a capacidade de explicar, apreender, compreender e enfrentar criticamente situações novas, de modo que cada indivíduo organiza seu processo intelectual ao longo de sua história de vida. Assim, toda ação, mesmo que singela, realizada pelos gestores participantes da pesquisa, em seu EES, foi considerada como um bom resultado para o pesquisador, pois na região de Carajás, a qual estamos inseridos, falta políticas públicas para o incentivo da economia solidária, falta oportunidades de formação para grupos marginalizados e consequentemente oportunidades para que pessoas em situação de vulnerabilidade social possam ter opção de sobrevivência.

\section{CONSIDERAÇÕES}

Os Empreendimentos Econômicos Solidários veem proporcionando a sociedade atual uma alternativa na geração de renda, e nesse sentido, faz-se necessário dar apoio à sua gestão. Com a realização da pesquisa percebeu-se que os EES do município de Parauapebas ainda buscam a efetivação da autogestão, pois muitas vezes eles não conseguem dar um retorno esperado para os seus sócios, seja em questões relacionadas a gestão participativa, ou por não gerar uma renda adequada.

Nesse sentido, podemos evidenciar a falta de formação para os membros dos EES, que ficou manifesta durante a primeira entrevista através do grupo focal, que gera dificuldades, desde a aceitação para os cargos de gestão, até a execução de pequenas tarefas realizadas por cada cooperado. A formação deve ser contínua para garantir a autogestão dos empreendimentos, pois a busca e a prática de novos conhecimentos poderá garantir as expectativas internas e 
externas. Devido à falta de formação para os membros dos EES, muitos gestores ainda utilizam somente da intuição para tomar decisões, que por muitas vezes conduzem a caminhos não eficazes na gestão dos empreendimentos. É necessário buscar novos conhecimentos para que se possa ampliar as alternativas de escolha, e não se valer apenas na intuição.

Os gestores dos EES entrevistados percebem a utilização da matemática nas suas cadeias produtivas e/ ou prestação de serviços, porém ainda não a utilizam de maneira sistemática como ferramenta na gestão. Isso ocorre pelo fato de não saberem relacionar os tópicos estudados na escola com a praticada no cotidiano dos EES, o que nos leva a entender como uma fragilidade nos processos de ensino e aprendizagem no âmbito escolar.

Assim, entende-se que a matemática na gestão dos empreendimentos econômicos solidários é algo necessário para atingir a autogestão e direcionar na tomada de decisões, pois dessa forma os sócios dos pequenos empreendimentos poderão sentir-se confiantes para participar de maneira efetiva da gestão. Acredita-se também, que, a forma de aproximação da matemática e a gestão dos EES acontece por meio da etnomatemática, pois valorizando os conhecimentos adquiridos culturalmente, pode-se desenvolver tópicos matemáticos para a gestão, dando maior sentido para os conhecimentos existentes.

Com a realização das oficinas, os EES do município de Parauapebas/PA, tiveram a oportunidade de contato com uma matemática voltada para a gestão, o que colaborou de maneira expressiva na mudança de atitudes em seu cotidiano. Pequenas ações como adotar um diário de produção ou de serviço, refletir sobre a tomada de decisão, revelam o envolvimento e percepção dos conceitos matemáticos para a gestão.

No desenvolvimento da pesquisa, os EES de Parauapebas/PA mostraram-se interessados em uma espécie de consultoria, pois, ao serem abordados nos primeiros contatos, deixavam claro o desejo de ter alguém para resolver os problemas existentes, diagnosticar a viabilidade de seus trabalhos e até ajudar na realização de parcerias para venda de seus produtos. $\mathrm{Na}$ realização das oficinas, além de desenvolver tópicos matemáticos para a gestão, também necessitou sensibilizar os gestores de que não haveria milagre, e sim apoio para que pudessem conseguir a autogestão.

Outra fragilidade da pesquisa, foi o tempo destinado aos trabalhos, pois não foram abordados todos os tópicos julgados necessários pelo pesquisador. Porém, existiam muitos entraves em relação à presença dos gestores nas oficinas, o que acabou ficando acordado somente em quatro encontros. Também vale frisar a necessidade de o coordenador das oficinas ser ponderador nas discussões, pois os gestores dos EES costumam trazer experiências e a necessidade de verbalizá-las, o que poderá atrapalhar o cronograma das atividades. 
Acredita-se que essa pesquisa não esgota as possibilidades de investigação de contribuições da matemática na gestão dos EES, e sim podemos entendê-la como precursora das investigações, pois existem necessidades, e o ensino de matemática fora da escola formal pode contribuir para o desenvolvimento de uma socidade mais autônoma.

\section{REFERÊNCIAS}

ASSEBURG, H. B.; GAIGER, L. I. A economia solidária diante das desigualdades. Revista de Ciências Sociais, v. 50, n. 3, p. 499-533, 2007.

BARDIN, L. Análise de Conteúdo. Lisboa, Portugal; Edições 70, LDA, 2016.

BARROS, M. F. Um estudo comparado sobre gestão emancipadora em organizações comunitárias: a comparação Bahia (Brasil) e Québec (Canadá). Gestão \& PlanejamentoG\&P, v. 1, n. 6, p. 57-69, 2008.

BRANDÃO, C. R. Saber e ensinar. Três estudos de educação popular. Campinas: Papirus, 1986.

D’AMBROSIO, U. Educação Matemática: da teoria à prática. Campinas, SP: Papirus Editora, 1996.

D’AMBROSIO, U. Sociedade, cultura, matemática e seu ensino. Educação e Pesquisa, São Paulo, v. 31, n. 1, p. 99-120, jan/abr. 2005.

D’AMBROSIO, U. O Programa Etnomatemática: uma síntese. Acta Scientiae, Canoas, v.10, n. 1, p. 7-16, jan. /jun. 2008.

DUARTE, C. G.. Etnomatemática, currículo e práticas sociais do "mundo da construção civil". Educação Unisinos, v. 8, n. 15, p. 195-215, 2004.

GADOTTI, M. A questão da educação formal/não-formal. Sion: Institut Internacional des Droits de $1^{\circ}$ Enfant, p. 1-11, 2005.

GARCIA, R. M. Os requisitos de um programa de treinamento de cooperativas. Revista de Administração de Empresas, v. 21, n. 1, p. 39-45, 1981.

MACHADO, S. M. C. F. Gestão de Cooperativa: um estudo de caso. 2006. Dissertação de Mestrado. Fundação Visconde de Cairu.

MENEGHETTI, R. C. G.. Educação matemática e economia solidária: Uma aproximação por meio da etnomatemática. Revista Latinoamericana de Etnomatemática: Perspectivas Socioculturales de la Educación Matemática, v. 6, n. 1, p. 40-66, 2013.

MENEGHETTI, R. C. G.; DAltoso JR, S. L. Etnomatemática no Contexto de Empreendimentos em Economia Solidária: o caso de uma marcenaria coletiva feminina. Zetetike, v. 21, n. 1, p. 53-76, 2013. 
MOREIRA, I. de C. A inclusão social e a popularização da ciência e tecnologia no Brasil, Revista Inclusão Social (IBICT - Instituto brasileiro de informação em Ciência e Tecnologia), v. 1, n. 2, 2006.

MORGAN, D. L. Focus groups as qualitative research. Thousand Oaks. Sage publications, 1996.

MOTCHANE, J. Economia social e economia solidária: álibi ou alternativa ao neoliberalismo. Textos Sobre Economia Solidária, v. 2, p. 111-116, 2007.

NAKAYASU, G. N.; SOUSA, A. F. de. Planejamento e controle financeiro: Economic value added (EVA) como instrumento de controle interno. Seminário de Administração, v. 7, 2004.

PEREIRA, R. M. Fórum de Economia Solidária do Distrito Federal e Entorno. Revista toque solidário. Texto digital. Abril de 2014. Disponível em: http://www.ecosolbasebrasilia.com.br/wpcontent/uploads/2014/05/revista_ts_dia_29.pdf acessado em: 30/11/2017.

PINHEIRO, R. P.; STROHSCHOEN, A. A. G. O ensino de matemática na gestão dos empreendimentos econômicos solidários (EES): uma aproximação por meio da etnomatemática. Revista Dynamis, v. 25, n. 1, p. 78-93, 2019.

SCHNEIDER, J. O. A doutrina do cooperativismo nos tempos atuais. Cadernos Cedope. São Leopoldo, v. 6, n. 12, p. 7-23, 1994.

VERGARA, S. C. Gestão de Pessoas. São Paulo: Atlas, 2009.

Submetido em: 07 de janeiro de 2020 .

Aprovado em: 21 de janeiro de 2020. 